\title{
New SR Drive with Integrated Charging Capacity for Plug-in Hybrid Electric Vehicles (PHEVs)
}

\author{
Yihua Hu, Member, IEEE, Xueguan Song, Wenping Cao, Senior Member, IEEE, and Bing Ji, Member, IEEE
}

\begin{abstract}
Plug-in hybrid electrical vehicles (PHEVs) provide much promise in reducing greenhouse gas emissions and thus a focal point of research and development. Existing on-board charging capacity is effective but requires the use of several power conversion devices and power converters, which reduce the reliability and cost-efficiency. This paper presents a novel three-phase SR motor drive with integrated charging functions (including ICE and grid charging). The electrical energy flow within the drivetrain is controlled by a power electronic converter with less power switching devices and magnetic devices. It allows the desired energy conversion between the engine generator, the battery and the SR motor under different operation modes. Battery charging techniques are developed to operate under both motor driving mode and standstill charging mode. During the magnetization mode, the machine's phase windings are energized by the DC-link voltage. The power converter and the machine phase windings are controlled with a three-phase relay to enable the use of the AC-DC rectifier. The power converter can work as a Buck-Boost type or a Buck-type DC-DC converter for charging the battery. Simulation results in Matlab/Simulink and experiments on a $3 \mathrm{~kW}$ SR motor validate the effectiveness of the proposed technologies, which may have significant economic implications and improve the PHEVs' market acceptance.
\end{abstract}

Index Terms-Battery chargers, DC-DC power conversion, hybrid electric vehicles, integrated chargers, power conversion, power MOSFETs, propulsion.

\section{INTRODUCTION}

$\mathrm{O}$ VER the last two decades, electric vehicle and plug-in hybrid electric vehicle (EV/PHEV) technologies have taken a significant leap forward, primarily aided by advances in electrical motor drives, power converters, batteries and system configuration. However, the range anxiety, long recharging times and high cost remain to be barriers to limit their widespread [1]-[3]. EVs/PHEVs represent a cost-sensitive market and new technologies are still evolving to improve their system performance and component integration while driving down the cost. Historically, high-performance permanent-magnet (PM) machines are the preferred motor drive option owing to their high power density and

Manuscript received May 31, 2013; revised November 12, 2013 and January 10, 2014; accepted January 25, 2014.

Copyright (c) 2014 IEEE. Personal use of this material is permitted. However, permission to use this material for any other purposes must be obtained from the IEEE by sending a request to pubs-permissions@ieee.org.

Y. Hu is with the Department of Electronic \& Electrical Engineering, University of Strathclyde, Glasgow, G1 1XQ, U.K.

W. Cao is with the School of Electronics, Electrical Engineering and Computer Science, Queen’s University Belfast, Belfast, BT9 5AH, U.K. (correspondence: w.cao@qub.ac.uk)

X. Song and B. Ji are with the School of Electrical and Electronic Engineering, Newcastle University, Newcastle upon Type, NE1 7RU, U.K. high-efficiency. Nonetheless, these permanent magnets (e.g. $\mathrm{NdFeB}$ ) are made of rare-earth materials which have limited reserve and significant environmental impacts. Recently, concerns over the reserve and supply security has driven a move towards developing rare earth-free or rare earth-less machines [3]-[7]. Among these, switched reluctance machines (SRMs) have received increasing attention in electrified automobiles. They have shown advantageous performance in terms of low cost, high robustness and reliability, high temperature and high speed operation [3]-[5][8]-[13].

In electric vehicles or plug-in hybrid electric vehicles, the on-board charger is limited to Level-1 charging power level with the charging power less than $3 \mathrm{~kW}$ and the input voltage less than $230 \mathrm{~V}$ due to weight, space and cost constraints. As a result, the charging time for passenger cars is typically 5-12 hours. Levels 2 and 3 can provide faster charging capability and have started to penetrate into the EV market [14][15]. More information about charging power levels are given in Table I.

$$
\text { TABLE I }
$$

ChARging POWER LEVELS (PARTIALly FROM [16])

\begin{tabular}{|c|c|c|c|}
\hline Power level types & Level 1 & Level 2 & Level 3 \\
\hline \multirow[t]{2}{*}{ Supply voltage } & $120 \mathrm{Vac}(\mathrm{US})$ & $240 \mathrm{Vac}(\mathrm{US})$ & 208-600 Vac \\
\hline & $230 \mathrm{Vac}(\mathrm{EU})$ & $400 \mathrm{Vac}(\mathrm{EU})$ & or Vdc \\
\hline Max current & $10-16 \mathrm{~A}$ & $16-32 \mathrm{~A}$ & $>32 \mathrm{~A}$ \\
\hline \multirow[t]{2}{*}{ Mains connection } & On-board & On-board & Off-board \\
\hline & 1-phase & 1/3-phase & 3-phase \\
\hline Typical use & $\begin{array}{l}\text { Home or office } \\
\text { convenience } \\
\text { outlet }\end{array}$ & $\begin{array}{l}\text { Private or public } \\
\text { outlet }\end{array}$ & $\begin{array}{l}\text { Commercial, } \\
\text { analogous to } \\
\text { filling station }\end{array}$ \\
\hline $\begin{array}{l}\text { Energy supply } \\
\text { interface }\end{array}$ & $\begin{array}{l}\text { Convenience } \\
\text { outlet }\end{array}$ & Dedicated EVSE & $\begin{array}{l}\text { Dedicated } \\
\text { EVSE }\end{array}$ \\
\hline Power level & $\leq 3.7 \mathrm{~kW}$ & $3.7-22 \mathrm{~kW}$ & $>50 \mathrm{~kW}$ \\
\hline Charging time & 11-36 hours & 1-6 hours & 0.2-1 hour \\
\hline Battery capacity & $16-50 \mathrm{kWh}$ & $16-50 \mathrm{kWh}$ & $16-50 \mathrm{kWh}$ \\
\hline Recharge range/hour ${ }^{\mathrm{a}}$ & $<20 \mathrm{~km}$ & $20-110 \mathrm{~km}$ & $>110 \mathrm{~km}$ \\
\hline
\end{tabular}

${ }^{\mathrm{a}}$ Assuming an average consumption of $20 \mathrm{kWh} / 100 \mathrm{~km}$.

New fast charging technologies are developing rapidly. A current trend is to develop high power on-board chargers to overcome range limitations [17][18]. This is achieved by improving converter technologies [19], integrating the charger with the converter [20], or integrating the charger with the drive motor [21]-[23]. The first route is exampled in [19], which describes a three-port DC-DC converter with power factor correction. The second route is presented in [20] by integrating a bidirectional AC-DC charger with the DC-DC converter. In this case, the charging system can control energy flow between the high voltage bus and the battery pack but its circuitry is complicated and the available power flow modes are limited. The third route is to integrate the on-board charger with the drive motor so as to utilize the machine windings for charging purposes. A $20 \mathrm{~kW}$ PM split-phase motor drive is specially 
design for EV charging [21] but it suffers from low charging power $(<3 \mathrm{~kW})$ and high harmonic contents in the back electromotive force (EMF). Compared to PM motor drives, reluctance motor drives are more suited for mass production EV/PHEV applications primarily owing to their rare earth-free feature and wide range torque-speed characteristics. A $2.3 \mathrm{~kW}$ SRM in [22] with an asymmetrical half-bridge converter can provide on-board charging and power factor correction functions. However, a boost-type front-end DC-DC converter is externally equipped, making this topology less practical and flexible for the target application. Based on the same motor, an integrated SRM-charger is later developed [23] to use standard three-phase intelligent power modules (IPMs) for building a four-phase full-bridge converter. This modularization makes easier for mass production but the use of a full-bridge topology reduces the system reliability (e.g. shoot-through issues). Moreover, the charging mode with the DC voltage supply is omitted, which is relevant to this work. Given that there does not exist a satisfactory on-board motor charger for PHEVs, this work is set out to fill the gap by proposing a new integrated versatile SR motor charger.

Generally, the on-board chargers are equipped with AC-DC rectification and voltage regulation in order to achieve a required voltage level. However, they are difficult to meet the varying input and output voltage/power requirements. From the input side of the charger, the options can be either DC or AC (single-phase or three-phase). Nevertheless, there is no consensus on the voltage/power levels in industry. From the output side, the battery would exhibit a wide voltage range under different state-of-charge (SOC) conditions and charging currents.

This paper presents a digital signal processor (DSP)-based SR motor drive for PHEVs with integrated charging capacity. There are two main working modes for PHEVs with the proposed chargers: driving and charging. During the driving mode, the SR motor can be powered directly from the engine-generator set, the battery, or a combination of the two. During the charging mode, a Buck-Boost DC-DC converter or a buck DC-DC converter can be selected to suit the voltage levels of the power source and onboard battery for charging. The novelty lies in that the on-board charger utilizes SR machine windings and fewer power switches for fast charging, and the power source can be either the grid or the internal combustion engine (ICE) generator; either DC or AC (single-phase or three-phase) power supply.

\section{PROPOSED SR MOTOR DRIVE}

A schematic diagram of the proposed PHEV electrical drive is shown in Fig. 1. It includes an ac generator $(G)$, a diode bridge rectifier $(R E)$, a DC link capacitor $(C)$, a modified C-dump converter, and a battery pack $(B)$. The drive system can provide required drive torque and battery charging in two different operational modes. Besides, the relays $R, J_{1}$ and $J_{2}$ are added to the circuit to achieve different operational modes.

The generator is mechanically coupled with a small internal combustion engine and thus produces three-phase AC power as the output. The AC power is then converted into DC by a three-phase rectifier so as to power the SR motor and to charge battery. The C-dump converter only requires four power metal oxide semiconductor field effect transistors (MOSFETs) switches and four diodes to allow for independent phase current control and phase overlapping.

The power flow between the generator, SR motor and battery for motoring, generating and charging operations are shown in Fig. 2.

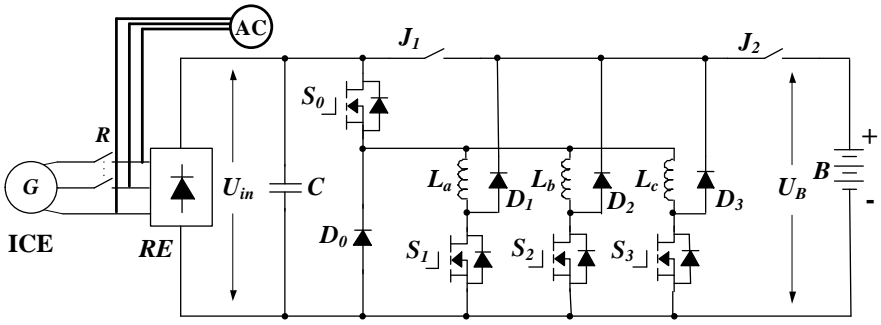

Fig. 1. Proposed three-phase SR motor drive with an on-board charger.

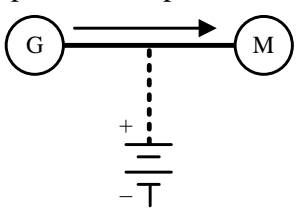

(a)

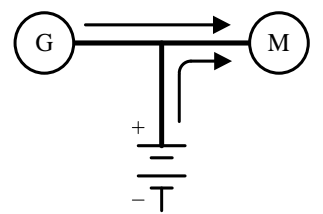

(c)

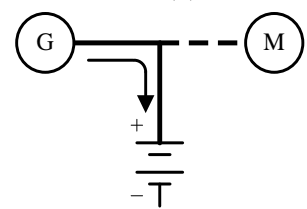

(e)

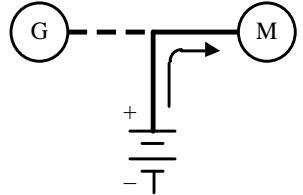

(b)

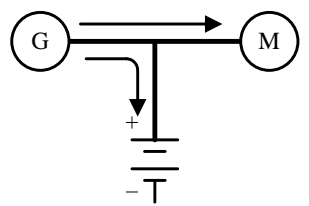

(d)

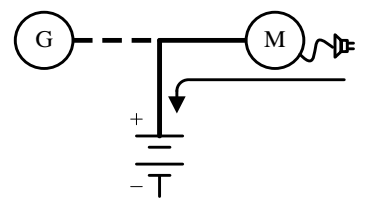

(f)
Fig. 2. Power flow for motoring (a-d), generating (e) and charging (f).

\section{A. The Motor Drive Modes}

In the motor drive modes, $R$ is closed for propulsion. The PHEV can be operated with the generator-alone, battery-alone, hybrid power supply or hybrid drive-charging.

\section{1) Configuration of the generator-alone drive}

When operated with the generator-alone mode, $R$ is closed and $J_{2}$ is open in Fig. 1. This forms a commonly used $(n+1)$ switch converter (also known as the Miller converter). Traditionally, the operation of the Miller converter depends on the switch $S_{0}$. If it is broken or open-circuited, the converter can not operate. Therefore this topology is not as prevalent as unsymmetrical inverters used in $\mathrm{HEV} / \mathrm{EV}$ applications. Besides, their phase isolation can also provide fault tolerance.

In this proof-of-concept work, a MOSFET-based converter is developed to control a $3 \mathrm{~kW}$ prototype motor drive. In the full-scale implementation, press pack IGBTs are employed to overcome the issue associated with the Miller converter. Since these devices have unique short-circuit characteristics under fault conditions, the proposed topology can still operate by angle control in the event of a device failure.

Moreover, the proposed topology utilizes less switching devices (only 4 active switches) and diodes but offers similar 
functionality to a 6-IGBT unsymmetrical inverter for the target application. Power flow in this mode is shown in Fig. 2(a).

2) Configuration of the battery-alone drive

In this mode, the ICE is shut off and $J_{1}-J_{2}$ are switched on. Effectively it also forms a Miller converter for the SR motor drive. The vehicle is operating at the pure electric propelling mode and its power flow between the battery pack and the SRM are illustrated in Fig. 2(b).

3) Configuration of the hybrid drive

In the hybrid drive model, $J_{1}$ and $J_{2}$ are closed and the power flow between the power sources (generator and battery) and the sink (motor) are controlled by the electric power converters. As in Fig. 2(c), the SR motor can be powered by a combination of the generator and battery pack to meet a heavy load condition, such as rapid acceleration or steep hill climbing. 4) Configuration of the hybrid drive-charging

At light load conditions, the generator drives the vehicle and charges the battery simultaneously if the SOC of the battery reaches a low limit. The generator's output power is split between the traction SR motor and the battery as shown in Fig. 2(d). In this case, the engine operates normally in its optimal region for fuel efficiency and low emissions while the battery pack acts as an energy buffer, wherein it is responsible for both the peaking power required by additional traction demand and regenerative energy (e.g. downhill or braking).

\section{B. The Generating Mode}

This is the mode for the generator to charge the battery without any involvement of the SR drive, as shown in Fig. 2(e). This is different to the regenerative operation.

\section{The Battery Charging Mode}

The battery pack can be charged by the external power supply, whose power flow is demonstrated in Fig. 2(f). When in this charging mode, the drive motor and the gears need to be disengaged for safety purposes. In addition, the relay $R$ is also open to disconnect the three-phase windings. This enables single-phase or three-phase charging from the rectifier.

A three-phase non-isolated DC-DC converter system is formed by the phase windings and switches, providing high efficiency and power density. By controlling the switches $S_{0}-S_{3}$, either a Buck-Boost or a Buck DC-DC converter can be configured to match the different voltage levels of the power source and batteries.

\section{1) Buck-boost type charging}

When the input voltage is lower than the battery voltage, $S_{0}$ is turned on, and $S_{1}, S_{2}$ and $S_{3}$ are controlled simultaneously with the same pulse-width modulation (PWM) scheme. The three-phase circuit is given in Fig. 3, assuming identical inductors and switches in each phase. Because the three phases are connected in parallel and the on-state resistance of power MOSFETs has a positive temperature coefficient, the current in each phase is balanced so that the power switches are equally stressed.

\section{2) Buck type charging}

When the input voltage is higher than battery voltage, the switching devices $S_{1}, S_{2}$ and $S_{3}$ are turned off and $S_{0}$ is controlled with a PWM scheme. The winding inductances of

SRM are connected in parallel in this configuration, as shown in Fig. 4, wherein $L_{\mathrm{eq}}$ denotes the equivalent inductance.

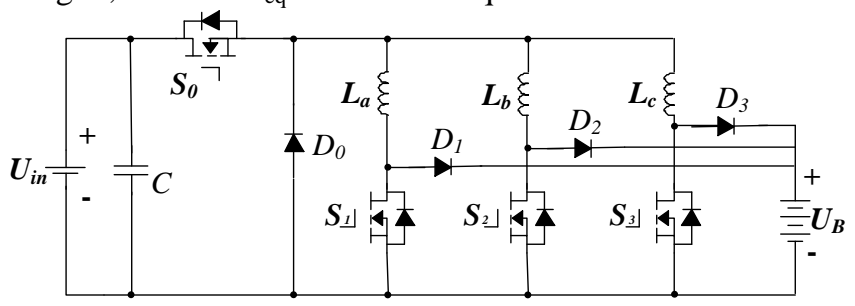

Fig. 3. Configuration of the Buck-Boost converter.

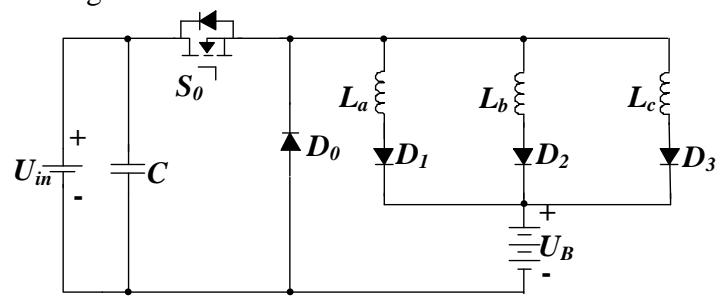

Fig. 4. Configuration of the Buck type charging.

\section{CONTROL SCHEME FOR THE INTEGRATED CHARGER}

The battery charging can be achieved under the motor drive and battery charging conditions.

\section{A. The Motor Drive-Charging Control}

In the motor drive mode, both the SR motor speed and charging current are regulated by controlling the commutation angle of each phase switching device $S_{1}, S_{2}$ and $S_{3}$, and applying PWM control to the main switch $S_{0}$. In this mode, there are four operating states: a magnetizing state, a freewheeling state, and two battery charging states. The four states are illustrated in Fig. 5 with phase $a$ as an example.

For SR motors, there is good magnetic isolation between phases [23] and thus the mutual inductance is negligible. If the voltage drop across switches and diodes are also ignored, the phase voltage of the SRM can be expressed as

$$
\mathrm{U}_{\mathrm{in}}=\mathrm{R}_{\mathrm{Lk}} \mathrm{i}_{\mathrm{Lk}}+\frac{\mathrm{d} \lambda\left(\mathrm{i}_{\mathrm{Lk}}, \theta_{\mathrm{r}}\right)}{\mathrm{dt}}=\mathrm{R}_{\mathrm{Lk}} \mathrm{i}_{\mathrm{Lk}}+\frac{\partial \lambda\left(\mathrm{i}_{\mathrm{Lk}}, \theta_{\mathrm{r}}\right)}{\partial \mathrm{i}_{\mathrm{Lk}}} \cdot \frac{\partial \mathrm{i}_{\mathrm{Lk}}}{\partial \mathrm{t}}+\frac{\partial \lambda\left(\mathrm{i}_{\mathrm{Lk}}, \theta_{\mathrm{r}}\right)}{\partial \theta_{\mathrm{r}}} \cdot \frac{\partial \theta_{\mathrm{r}}}{\partial \mathrm{t}}
$$

where $U_{i n}, i_{L k}, R_{L k}$ and $\lambda\left(i_{L k}, \theta_{\mathrm{r}}\right)$ are the phase voltage, phase current, phase winding resistance and phase flux linkage (excited by $i_{L k}$ ), respectively; $k=a, b, c$ phase. $\theta_{\mathrm{r}}$ indicates the rotor position relative to the stator. The phase incremental inductance $l$ and the back EMF $e_{\mathrm{Lk}}$ are

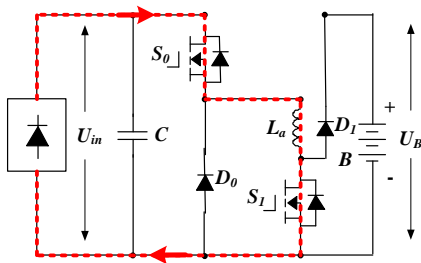

(a)

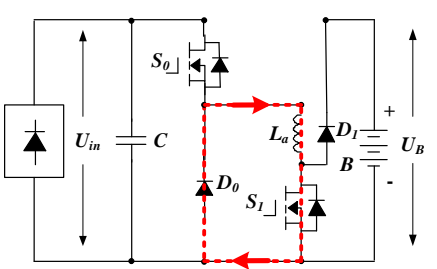

(c)

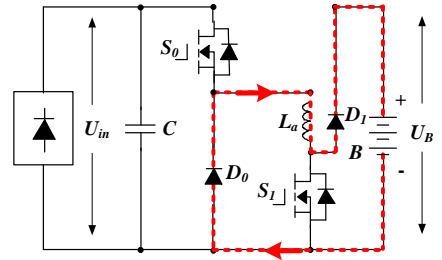

(b)

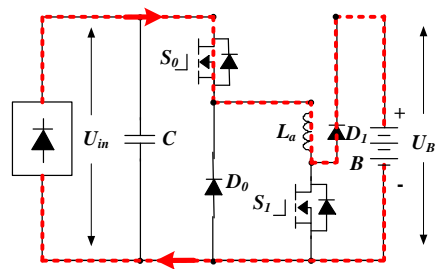

(d) 
Fig. 5. Four switching states during generator-alone drive. (a) Magnetizing. (b) Charging I. (c) Freewheeling. (d) Charging II.

$$
\begin{gathered}
\mathrm{l}=\partial \lambda\left(\mathrm{i}_{\mathrm{Lk}}, \theta_{\mathrm{r}}\right) / \partial \mathrm{i}_{\mathrm{Lk}} \\
\mathrm{e}_{\mathrm{Lk}}=\omega_{\mathrm{r}} \partial \lambda\left(\mathrm{i}_{\mathrm{Lk}}, \theta_{\mathrm{r}}\right) / \partial \theta_{\mathrm{r}}
\end{gathered}
$$

Eq. 1 can also be given by

$$
\mathrm{U}_{\mathrm{in}}=\mathrm{R}_{\mathrm{Lk}} \mathrm{i}_{\mathrm{Lk}}+\mathrm{l} \frac{\mathrm{di}}{\mathrm{dt}}+\mathrm{e}_{\mathrm{Lk}}
$$

When $S_{0}$ and $S_{1}$ are turned on during excitation as shown in Fig. 5(a), $L_{\mathrm{a}}$ is at magnetizing state. The phase $a$ winding is subjected to the positive DC bus voltage, and $U_{\text {in }}$ is powered by $G$ through switches $S_{0}$ and $S_{1}$. During this period, $L_{\mathrm{a}}$ is energized and torque is produced in the SR motor.

When $S_{0}$ and $S_{1}$ are off as in Fig. 5(b), the circuit is at the charging-I state. The stored energy in the phase winding is released to charge the battery $B$ through $D_{0}$ and $D_{1}$. The demagnetization current $i_{\text {Lk }}$ decays quickly. The phase voltage and current can be derived by

$$
\mathrm{U}_{\mathrm{B}}+\mathrm{R}_{\mathrm{Lk}} \mathrm{i}_{\mathrm{Lk}}+\frac{\mathrm{d} \lambda\left(\mathrm{i}_{\mathrm{Lk}}, \theta_{\mathrm{r}}\right)}{\mathrm{dt}}=0
$$

where $U_{B}$ is the battery voltage. The negative voltage across the phase winding can speed up the phase current decay and eliminate the generation of the braking torque.

When $S_{0}$ is turned off and $S_{1}$ is on as in Fig. 5(c), the phase $a$ current in $L_{\mathrm{a}}$ freewheels through $S_{1}$ and $D_{0}$. The phase voltage becomes zero. That is,

$$
\mathrm{R}_{\mathrm{Lk}} \mathrm{i}_{\mathrm{Lk}}+\frac{\mathrm{d} \lambda\left(\mathrm{i}_{\mathrm{Lk}}, \theta_{\mathrm{r}}\right)}{\mathrm{dt}}=0
$$

When $S_{0}$ is on and $S_{1}$ is off as shown in Fig. 5(d), the circuit is at the charging-II state. When $U_{i n}$ is larger than $U_{B}$, the phase winding can continue to charge the battery; otherwise the winding is demagnetized. In this configuration, all the phases can be controlled independently allowing overlap between the three phases, which is advantageous for high-speed SR motor operation. The phase voltage equation is given by

$$
U_{B}+R_{L k}+\frac{d \lambda\left(i_{L k}, \theta_{r}\right)}{d t}=U_{\text {in }}
$$

In SR motors, a defined voltage is applied to each phase with a controllable PWM duty cycle and a turn-on angle. The PWM is controlled by the duty ratio of the switches, and the effective phase voltage is modulated to have desired phase current waveform. The corresponding driving interval and charging interval are all changed accordingly as shown in Fig. 6(a). With turn-on angle control, the phase is energized in the minimum inductance region before the phase inductance rises, and so are the torque and battery charging current (see Fig. 6b). By turn-off angle control, the battery charging current can be controlled, as illustrated in Fig. 6(c). By controlling the PWM, turn-on angle and turn-off angle, the required torque and charging current can be realized.

\section{B. The Battery Charging Control}

In this mode, the battery is charged by the generator or by an external power source. The SR motor drive and winding inductance are used to incorporate new topology for different charging voltages. If the input voltage is lower than the battery voltage, the charger works in the Buck-Boost mode. When $S_{0}$ and $S_{1}$ turn on, the winding inductor $L_{\mathrm{a}}$ is charged by the input voltage, as shown in Fig. 7(a). The battery charged by the inductor freewheeling current is illustrated in Fig. 7(b).

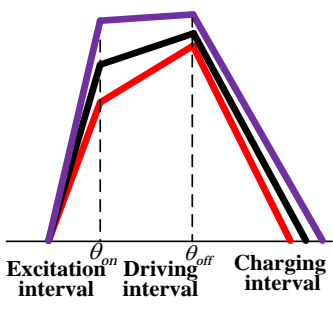

(a)

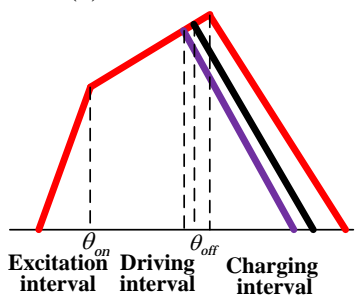

(c)

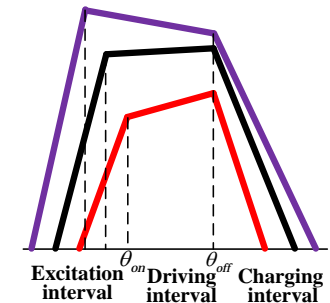

(b)
Fig. 6. Three control methods. (a) PWM control. (b) Turn on angle control. (c) Turn off angle control.

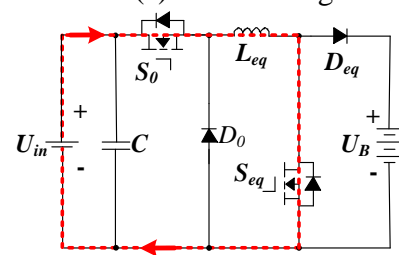

(a)

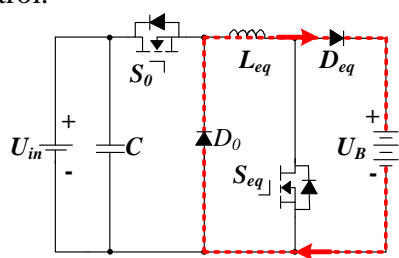

(b)

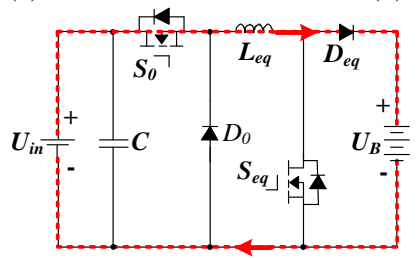

(c)

Fig. 7. Operation modes of the boost charging with (a) $S_{0}$ and $S_{1}$ turned on. (b) $S_{0}$ and $S_{1}$ turned off. (c) $S_{0}$ turned on and $S_{1}$ turned off.

In Fig. 7(c), the battery is simultaneously charged by both the input voltage and the inductor. The corresponding voltage equation can be expressed as:

$$
U_{\text {in }}-U_{B}=L_{e q} \frac{d i_{L}}{d t}
$$

Because the SR motor has a double saliency structure, the phase inductors $L_{\mathrm{a}}, L_{\mathrm{b}}$ and $L_{\mathrm{c}}$ are different depending on their rotor position. When three-phase power MOSFETs are operated as a single switch, three phase currents of different magnitudes flow to the battery simultaneously. In order to improve efficiency and thermal distribution, a current sharing control method is needed, which can be achieved by either pulse current control or constant voltage control. The two cases are illustrated in Fig. 8(a) and (b), respectively. In the pulse current control, equal current sharing is simply realized by specifying a reference current. In the constant voltage control, the current reference is calculated from the output voltage error in the proportional-integral (PI) control loop.

In the Buck type battery charging mode, $S_{0}$ is turned on and the input provides energy to the battery pack as well as to the inductor, as in Fig. 9(a). When $S_{0}$ is turned off, the inductor 
transfers its stored energy to the battery through $D_{0}$ as shown in Fig. 9 (b).

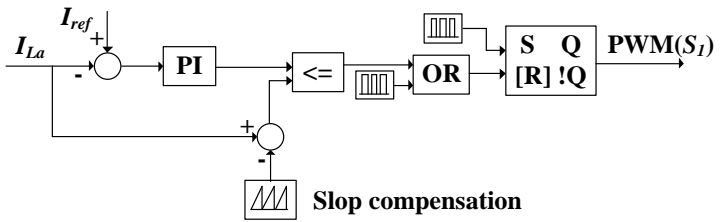

(a)

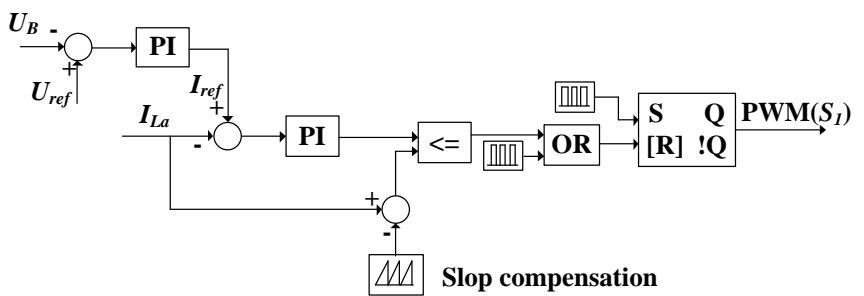

(b)

Fig. 8. Battery charging control. (a) Pulse current control. (b) Constant voltage control.

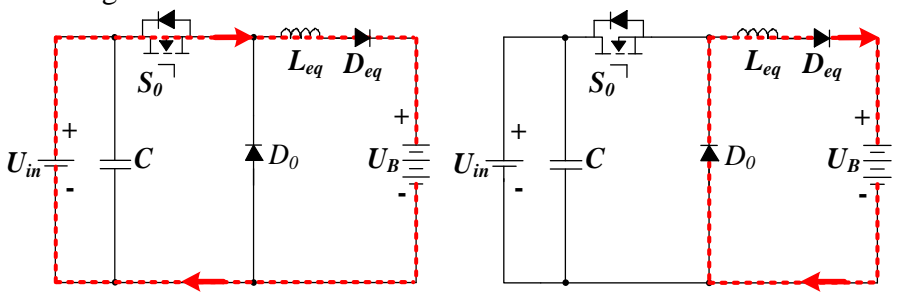

(a)

(b)

Fig. 9. Operation modes of the Buck charging with (a) $S_{0}$ turned on and (b) $S_{0}$ turned off.

The DC-DC converter can operate in both continuous and discontinuous modes. In the continuous conduction mode (CCM), the phase current can be expressed as

$$
i_{L k}(t)=\left\{\begin{array}{c}
I_{k 0}+\frac{I_{k m}-I_{k 0}}{D T_{s}} t, t \in\left[0, D T_{s}\right] \\
I_{k m}+\frac{I_{k 0}-I_{k m}}{(1-D) T_{s}}\left(t-D T_{s}\right), t \in\left[D T_{s}, T_{s}\right]
\end{array}\right.
$$

where $D, T_{\mathrm{s}}, I_{\mathrm{k} 0}$ and $I_{\mathrm{km}}$ represent the duty ratio, switching period, initial phase current and maximum phase current, respectively. By employing the three-phase equations $I_{\text {max }}=I_{a m}+I_{b m}+I_{c m}$ and $I_{\min }=I_{a 0}+I_{b 0}+I_{c 0}$, the charging current is expressed as

$$
i(t)=\left\{\begin{array}{c}
I_{\text {min }}+\frac{I_{\text {max }}-I_{\text {min }}}{D T_{s}} t, t \in\left[0, D T_{s}\right] \\
I_{\text {max }}-\frac{I_{\text {max }}-I_{\text {min }}}{(1-D) T_{s}}\left(t-D T_{s}\right), t \in\left[D T_{s}, T_{s}\right]
\end{array}\right.
$$

In the discontinuous conduction mode (DCM), the charging current is the pulse current. The winding current is

$$
i_{L k}(t)=\left\{\begin{array}{c}
\frac{I_{k m}}{D_{1} T_{s}} t, t \in\left[0, D_{1} T_{s}\right] \\
I_{k m}-\frac{I_{k m}}{D_{2} T_{s}}\left(t-D_{1} T_{s}\right), t \in\left[D_{1} T_{s},\left(D_{1}+D_{2}\right) T_{s}\right] \\
0, t \in\left[\left(D_{1}+D_{2}\right) T_{s}, T_{s}\right]
\end{array}\right.
$$

$$
i(t)=\left\{\begin{array}{c}
\frac{I_{\max }}{D_{1} T_{s}} t, t \in\left[0, D_{1} T_{s}\right] \\
I_{\max }-\frac{I_{\max }}{D_{2} T_{s}}\left(t-D_{1} T_{s}\right), t \in\left[D_{1} T_{s},\left(D_{1}+D_{2}\right) T_{s}\right] \\
0, t \in\left[\left(D_{1}+D_{2}\right) T_{s}, T_{s}\right]
\end{array}\right.
$$

\section{SIMULATION AND EXPERIMENTAL RESULTS}

In order to verify the proposed topology and control method, simulation in Matlab/Simulink and experiential work on a prototype are carried out.

\section{A. Simulation Tests}

A three-phase 12/8 SR motor drive-charger is modeled in the simulation. The generator-alone driving mode (Fig. 2d) is simulated under the angle control and PWM control. Due to the lagging phase current as a result of the phase winding inductance, the switch is turned on before the inductance rises and is turned off at the inductance rising region. Owing to the presence of the back EMF and the battery voltage, the phase current decreases quickly, as shown in Fig. 10. When the lagging turn-on angle is used (Fig. 11), the turn-off angle is triggered in the inductance decreasing reign, resulting in diminished torque and increased battery charging current. These offer a means of torque regulation over a wide speed range, which is of importance for constant current charging mode.

The individual phase of the SR motor is turned on at a constant turn-on angle, and two different dwell angles $\left(22.5^{\circ}\right.$ and $18.75^{\circ}$ ) are achieved by delaying the turn-off angles. Fig. 12 shows that the battery charging current can be controlled in accordance with the dwell angle. But this results in limited torque variations. The decaying phase current is controlled by the battery voltage level which can suppress the braking torque.

The effective voltage on the phase inductor can also be controlled by the duty ratio of the main switch. Fig. 13 provides comparisons of torque and current at different duty ratios of the main switch. Torque 1 and $i_{B 1}$ have higher duty ratios than Torque 2 and $i_{B 2}$, and thus higher torque and charging current.

Fig. 14 presents the simulation results of battery charging. The input voltage is $27 \mathrm{~V}$; the three winding inductances are 20 $\mathrm{mH}, 10 \mathrm{mH}$ and $5 \mathrm{mH}$, respectively; the battery voltage is $35 \mathrm{~V}$. By using the proposed current sharing control, the average phase current is approximately equal despite that the three phases have different current ripples.

\section{B. Experimental Tests}

A photo of the experiment setup is presented in Fig. 15. A programmable power supply is used to simulate power supply from the generator; A TMS320F28335 DSP is employed as the controller; a $39.5 \mathrm{~V}$ lead-acid battery is employed as the energy storage equipment. The test motor is a $12 / 8 \mathrm{SR}$ motor with the ratings of: $300 \mathrm{~V}$ voltage, $3 \mathrm{~kW}$ power and $1500 \mathrm{rpm}$ speed. A magnetic brake acts as the load with a rated torque of $10 \mathrm{Nm}$.

The charging current is expressed as 

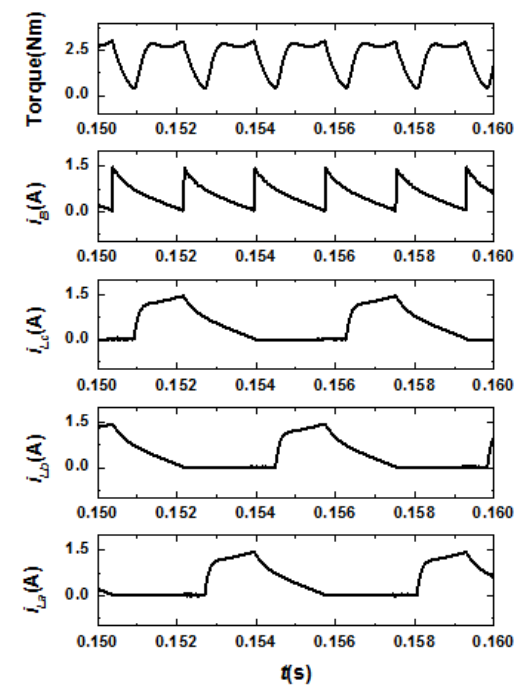

Fig. 10. Simulation results for the leading turn-on angle.
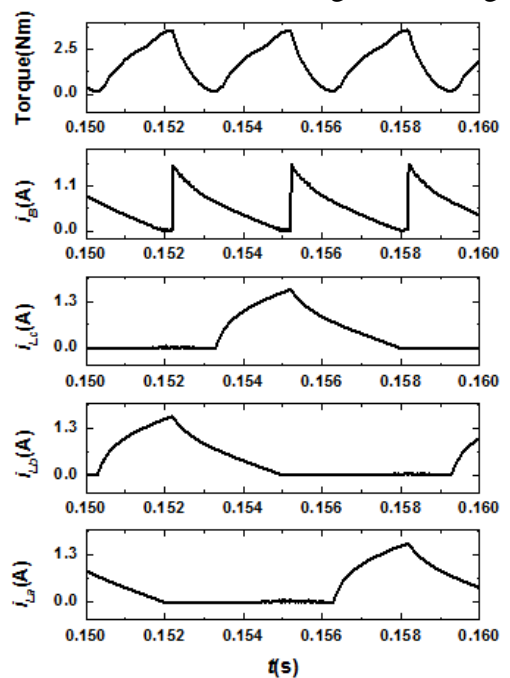

Fig. 11. Simulation results for the lagging turn-on angle.

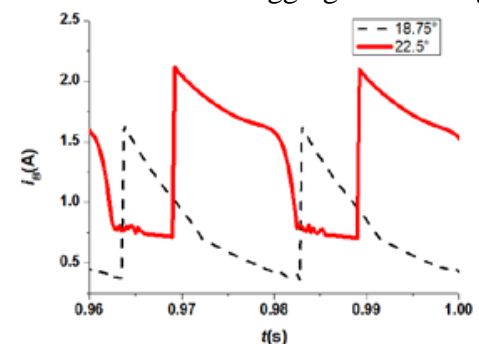

(a)

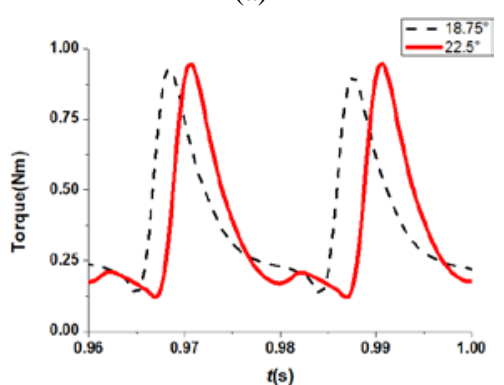

(b)

Fig. 12. Charging current and torque as a function of the turn-off angle. (a) Comparison of charging current. (b) Comparison of torque.
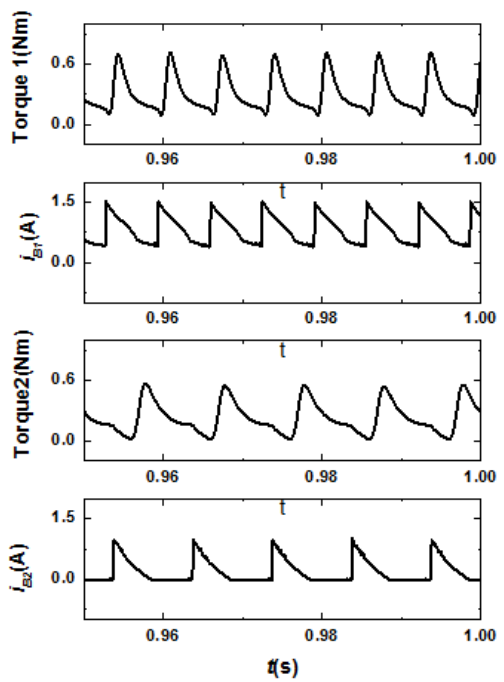

Fig. 13. Comparison at different duty ratios of $S_{0}$.
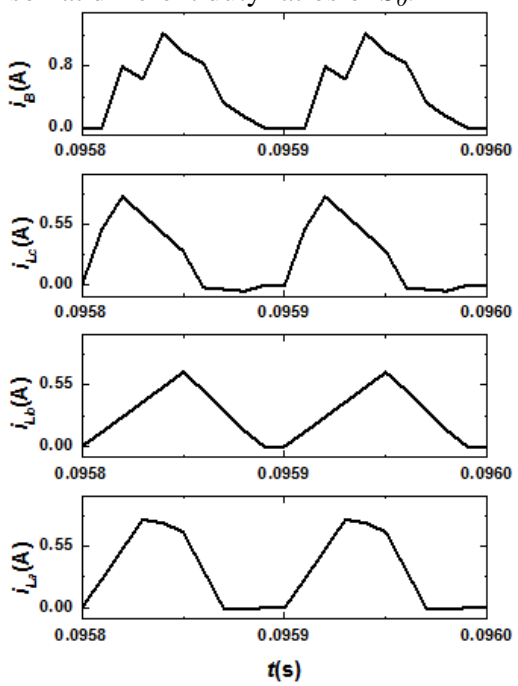

Fig. 14. Pulse current control.

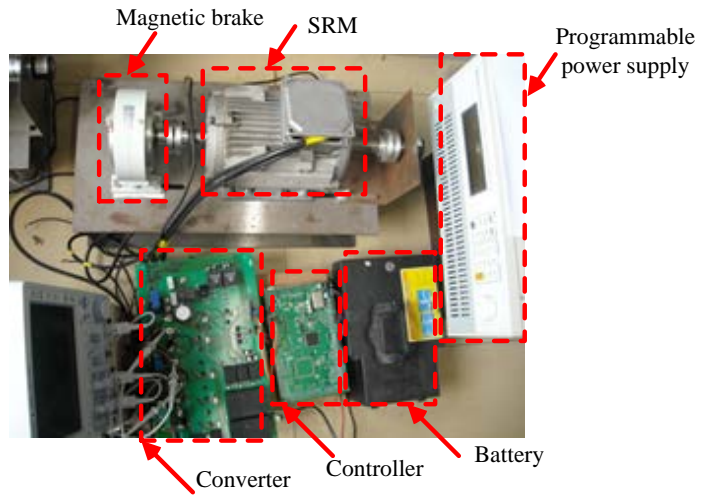

Fig. 15. Experimental setup of the proposed on-board charger.

Fig. 16 shows the experimental results for the turn-on angle control, with a $50 \mathrm{~V}$ input voltage and a $1 \mathrm{Nm}$ load torque. Fig. 16(a) and (b) agree well with the simulation results in Figs. 10 and 11, respectively. Fig. 17 presents the experimental results for the PWM control. As the effective voltage increases, the rotor speed and battery charging current increase. These results agree with the simulation results in Fig. 13. Experimental results in Fig. 18 (a) and (b) are for different turn-off angles with a constant turn-on angle. In this experiment, the battery voltage is set $13 \mathrm{~V}$. By delaying the turn-off angle, the battery 
charging current is increased, which coincides with the simulation results. Overall, the test results of the PWM control, turn-on angle control and turn-off angle control justify the effectiveness of the proposed control schemes.

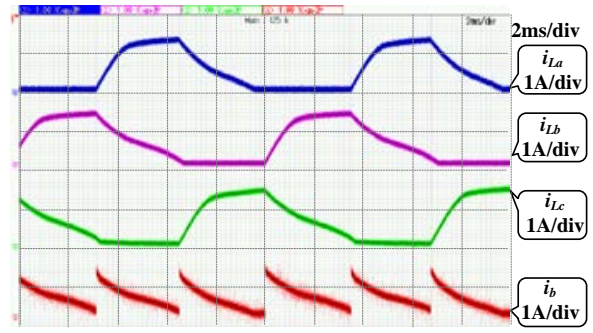

(a)

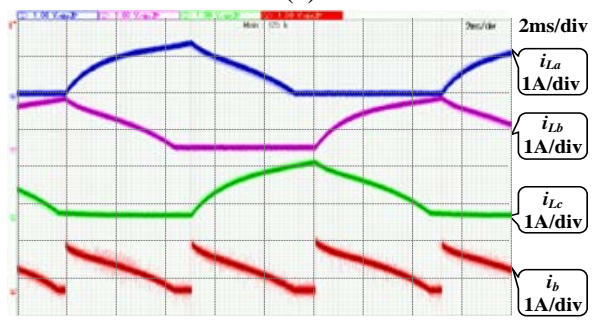

(b)

Fig. 16. Experimental results for the turn-on angle control. (a) Angle in advance (at $750 \mathrm{rpm}$ ). (b) Angle in lagging (at $500 \mathrm{rpm}$ ).

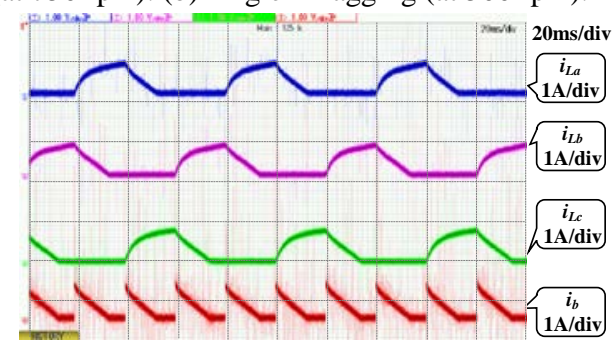

(a)

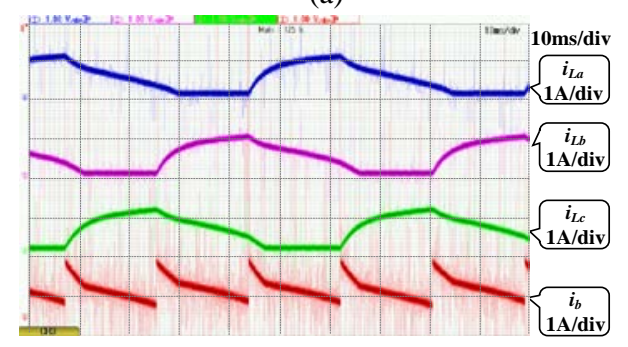

(b)

Fig. 17. Experimental results for the PWM control. (a) $18 \mathrm{~V}$ effective voltage (at $125 \mathrm{rpm}$ ). (b) $24 \mathrm{~V}$ effective voltage (at $150 \mathrm{rpm}$ ).

Fig. 18(c) shows experimental results for the high-speed operation at $1500 \mathrm{rpm}$, and Fig. 19 presents the transient progression resulting from sudden load changes. When the load increases from no-load to $1 \mathrm{Nm}$ as in Fig. 19(a), the speed is stabilized within $600 \mathrm{~ms}$. Similarly, when the load reduces from $1 \mathrm{Nm}$ to no-load, the machine speed is adjusted within $600 \mathrm{~ms}$, as in Fig. 19(b). Fig. 19(c) presents transient change with continues load relief. The speed can still be controlled easily. Fig. 19(d) and (e) show experimental results without and with braking, respectively. The machine speed decreases to zero within 200ms with braking. Fig. 19(f) demonstrates transient progression from the generator-alone drive mode to the battery-alone drive mode. As can be seen from these diagrams, the speed can be readily controlled at given speed demands (high or low speeds).

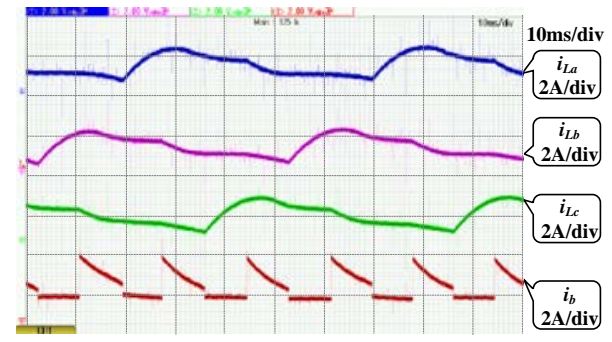

(a)

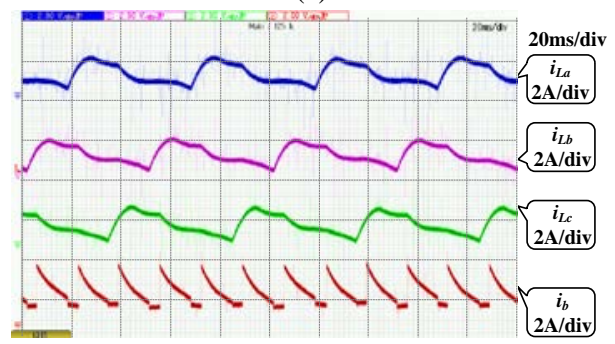

(b)

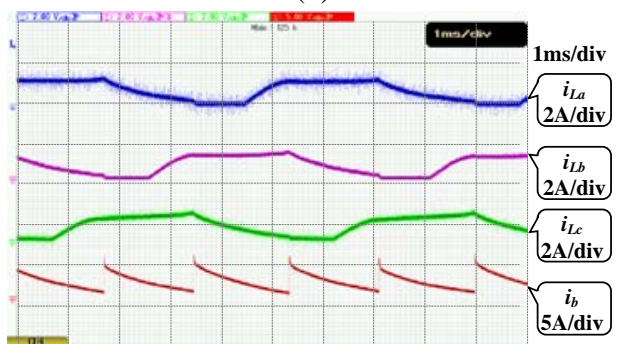

(c)

Fig. 18. Experimental results for the turn-off angle control and for high speed operation. (a) $22.5^{\circ}$. (b) $18.75^{\circ}$. (c) High-speed condition (at $1500 \mathrm{rpm})$.

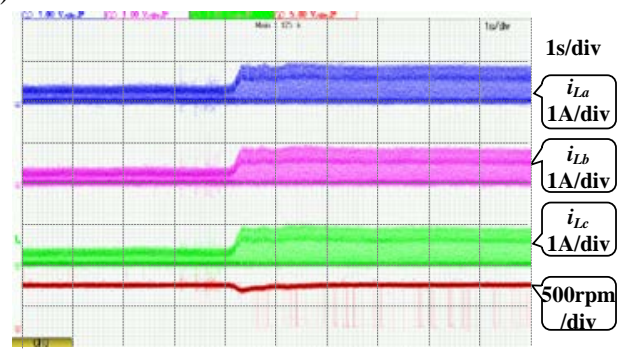

(a)

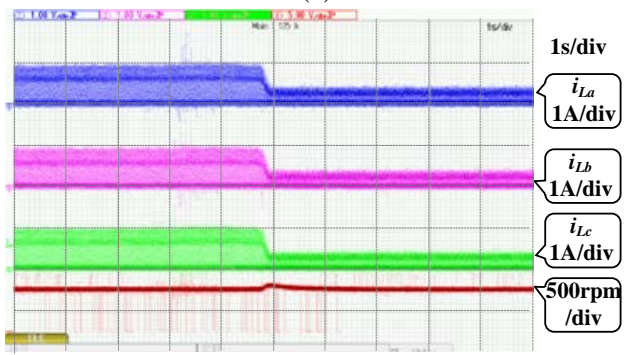

(b)

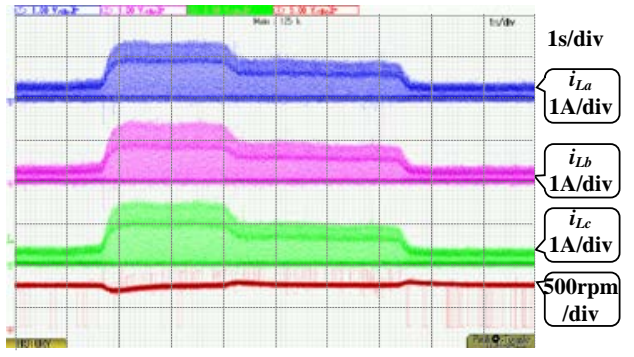

(c) 


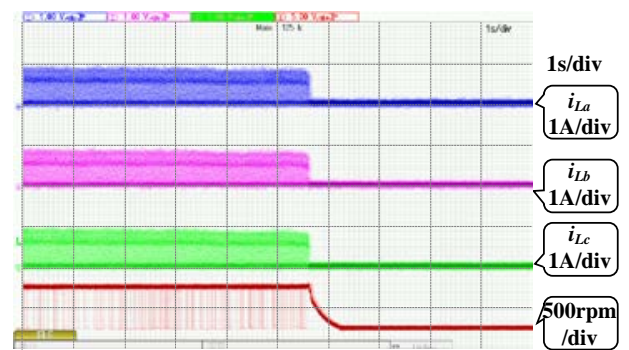

(d)

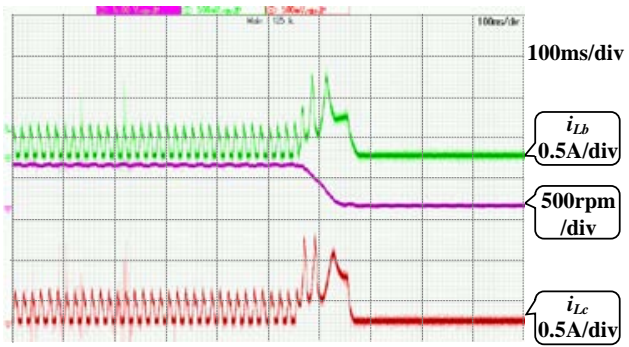

(e)

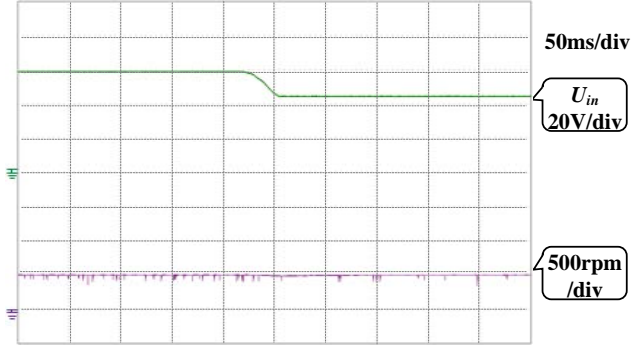

(f)

Fig. 19. Experimental results under transient conditions. (a) Abrupt load increase. (b) Abrupt load decrease. (c) Continuous load relief. (d) Without braking. (e) With braking. (f) Mode switching.

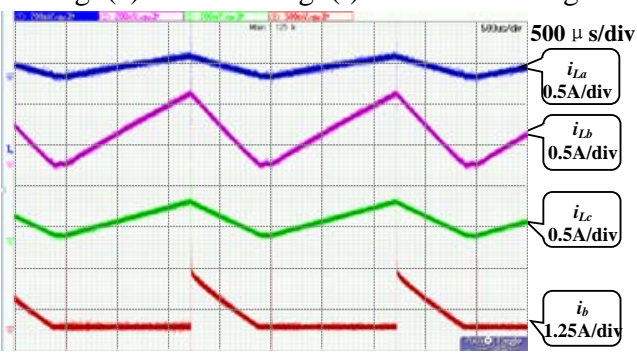

(a)

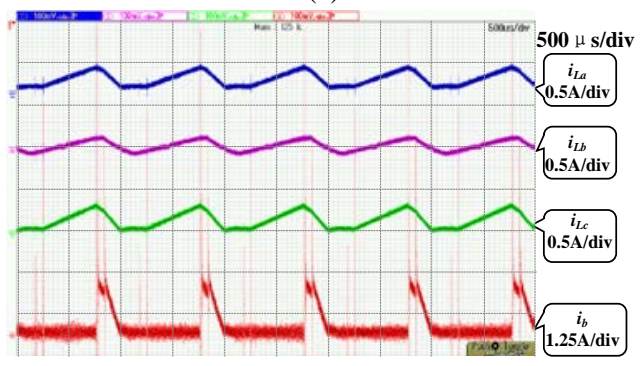

(b)

Fig. 20. Measured charging current of the Buck-Boost converter. (a) Without current sharing control. (b) With current sharing control.

The battery-charging modes are also tested under low and high input voltage conditions. When the input voltage (27 V) is lower than the battery voltage (39.5 V), the converter works in the Buck-Boost mode. Figs. 20(a) and (b) present the experimental results without and with the current sharing control, respectively. As can be seen, the peak currents are different without the current sharing control but become equal with the current sharing control.

When the input voltage $(60 \mathrm{~V})$ is higher than the battery voltage, the converter works in the Buck mode. Fig. 21 illustrates the DCM and CCM results for the $500 \mathrm{~Hz}$ switching frequency. In the DCM, the battery charging current is a pulse current while in CCM this is a continuous current.

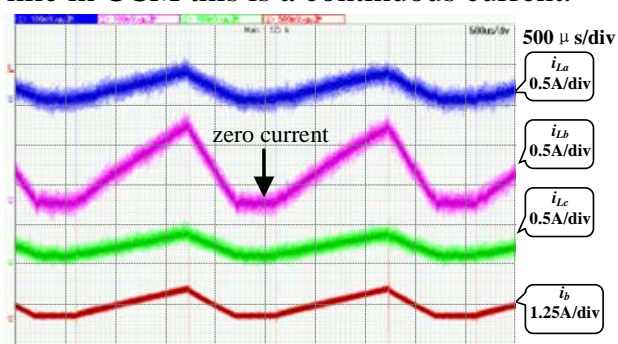

(a)

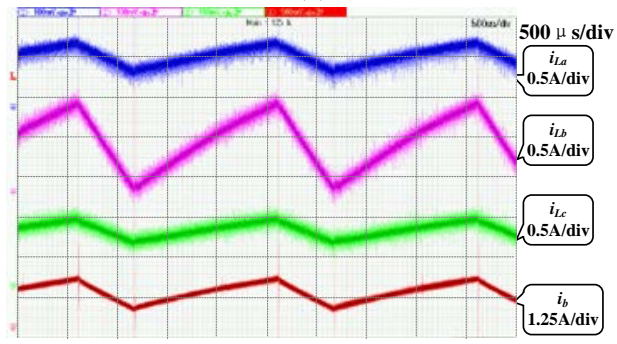

(b)

Fig. 21. Measured charging current of the Buck converter. (a) DCM mode with $D=0.56$. (b) CCM mode with $D=0.72$.

\section{CONCLUSIONS}

In order to enhance the market adoption of PHEVs, this paper has proposed a new SR motor drive used as an integrated grid/ICE charger for fast on-board charging.

The main contributions of this paper are: (i) a novel topology for PHEVs is developed which utilizes the on-board power supply and SR motor for battery charging and motor drive operations. (ii) the converter for driving/charging functions employs less power switching devices than conventional converters. (iii) the SR motor phase winding inductors are utilized for fast charging purposes. (iv) new battery charging control schemes are proposed to minimize the current distribution differences.

Since PHEVs represent a mass production industry, the developed technologies from this work will have significant economic implications in addition to environmental benefits. They can also be applied to unsymmetrical inverters but may not achieve the diverse functionality of mode switching described in this paper. However, because this is a proof-of-concept project, the power rating is still relatively low. In the further work, the motor-charger system will be scaled up to $60 \mathrm{~kW}$ based on press pack IGBT power devices. These devices have unique short-circuit features under fault conditions so that the proposed topology is capable of operating with angle control in the event of a device failure.

\section{REFERENCES}

[1] Munoz-Condes, P.; Gomez-Parra, M.; Sancho, C.; San Andres, M.A.G.; Gonzalez-Fernandez, F.J.; Carpio, J.; Guirado, R., "On condition maintenance based on the impedance measurement for traction batteries: 
development and industrial implementation," IEEE Trans. Industrial Electronics, vol.60, no.7, pp.2750-2759, July 2013.

[2] Chopra, S.; Bauer, P., "Driving range extension of EV with on-road contactless power transfer-a case study," IEEE Trans. Industrial Electronics, vol.60, no.1, pp.329-338, Jan. 2013.

[3] Bilgin, B.; Emadi, A.; Krishnamurthy, M., "Comprehensive evaluation of the dynamic performance of a 6/10 SRM for traction application in PHEVs," IEEE Trans. Industrial Electronics, vol.60, no.7, pp.2564-2575, July 2013.

[4] Takeno, M.; Chiba, A.; Hoshi, N.; Ogasawara, S.; Takemoto, M.; Rahman, M.A., "Test results and torque improvement of the 50-kW switched reluctance motor designed for hybrid electric vehicles," IEEE Trans. Industry Applications, vol.48, no.4, pp.1327-1334, 2012.

[5] Chiba, A.; Takano, Y.; Takeno, M.; Imakawa, T.; Hoshi, N.; Takemoto, M.; Ogasawara, S., "Torque density and efficiency improvements of a switched reluctance motor without rare-earth material for hybrid vehicles," IEEE Trans. Industry Applications, vol.47, no.3, pp.1240-1246, May-June 2011.

[6] Dorrell, D.G.; Knight, A.M.; Evans, L.; Popescu, M., "Analysis and design techniques applied to hybrid vehicle drive machines-assessment of alternative IPM and induction motor topologies," IEEE Trans. Industrial Electronics, vol.59, no.10, pp.3690-3699, Oct. 2012.

[7] Marques dos Santos, F. ; Anthonis, J. ; Naclerio, F. ; Gyselinck, J.; Van der Auweraer, H.; Sandoval Goes, L., "Multiphysics NVH modeling: simulation of a switched reluctance motor drivetrain for an electric vehicle," IEEE Trans. Industrial Electronics, in press.

[8] Chiba, A.; Takeno, M.; Hoshi, N.; Takemoto, M.; Ogasawara, S.; Rahman, M.A., "Consideration of number of series turns in switched-reluctance traction motor competitive to HEV IPMSM," IEEE Trans. Industry Applications, vol.48, no.6, pp.2333-2340, Nov. 2012.

[9] Xue, X.D.; Cheng, K.W.E; Ng, T.W.; Cheung, N.C., "Multi-objective optimization design of in-wheel switched reluctance motors in electric vehicles," IEEE Trans. Industrial Electronics, vol.57, no.9, pp.2980-2987, Sept. 2010.

[10] Bilgin, B.; Emadi, A.; Krishnamurthy, M., "Design considerations for switched reluctance machines with a higher number of rotor poles," IEEE Trans. Industrial Electronics, vol.59, no.10, pp.3745-3756, Oct. 2012.

[11] Desai, P.C.; Krishnamurthy, M.; Schofield, N.; Emadi, A., "Novel switched reluctance machine configuration with higher number of rotor poles than stator poles: concept to implementation," IEEE Trans. Industrial Electronics, vol.57, no.2, pp.649-659, Feb. 2010.

[12] Torkaman, H.; Afjei, E., "Comprehensive detection of eccentricity fault in switched reluctance machines using high-frequency pulse injection," IEEE Trans. Power Electronics, vol.28, no.3, pp.1382-1390, March 2013.

[13] Liang, J.; Lee, D.H.; Xu, G.; Ahn. J.W., "Analysis of passive boost power converter for three-phase SR drive," IEEE Trans. Industrial Electronics, vol.57, no.9, pp.2961-2971, Sept. 2010.

[14] Hui, S.Y.R.; Ho, W.W.C., "A new generation of universal contactless battery charging platform for portable consumer electronic equipment," IEEE Trans. Power Electronics, vol.20, no.3, pp.620-627, May 2005.

[15] Khaligh, A.; Dusmez, S., "Comprehensive topological analysis of conductive and inductive charging solutions for plug-in electric vehicles," IEEE Trans. Vehicular Technology, vol.61, no.8, pp.3475-3489, 2012.

[16] Yilmaz, M.; Krein, P.T., "Review of battery charger topologies, charging power levels, and infrastructure for plug-in electric and hybrid vehicles," IEEE Trans. Power Electronics, vol.28, no.5, pp.2151-2169, May 2013.

[17] Budhia, M.; Boys, J.T.; Covic; G.A.; Huang, C.U., "Development of a single-sided flux magnetic coupler for electric vehicle IPT charging systems," IEEE Trans. Industrial Electronics, vol.60, no.1, pp.318-328, Jan. 2013.

[18] Khaligh, A.; Dusmez, S., "Comprehensive topological analysis of conductive and inductive charging solutions for plug-in electric vehicles," IEEE Trans. Vehicular Technology, vol.61, no.8, pp.3475-3489, 2012.

[19] Aguilar, C.; Canales, F.; Arau, J.; Sebastian, J.; Uceda, J., “An integrated battery charger/discharger with power-factor correction,” IEEE Trans. Industrial Electronics, vol.44, no.5, pp.597-603, Oct 1997.

[20] Lee, Y.J.; Khaligh, A.; Emadi, A., "Advanced integrated bidirectional AC/DC and DC/DC converter for plug-in hybrid electric vehicles," IEEE Trans. Vehicular Technology, vol.58, no.8, pp.3970-3980, Oct. 2009.
[21] Haghbin, S.; Khan, K.; Zhao. S; Alakula, M.; Lundmark, S.; Carlson, O., "An integrated 20-kW motor drive and isolated battery charger for plug-in vehicles,” IEEE Trans. Power Electronics, vol.28, no.8, pp.4013-4029, Aug. 2013.

[22] Chang, H.C.; Liaw, C.M., "Development of a compact switched-reluctance motor drive for EV propulsion with voltage-boosting and PFC charging capabilities," IEEE Trans. Vehicular Technology, vol.58, no.7, pp.3198-3215, Sept. 2009.

[23] Chang, H.C.; Liaw, C.M., "An integrated driving/charging switched reluctance motor drive using three-phase power module," IEEE Trans. Industrial Electronics, vol.58, no.5, pp.1763-1775, May 2011.

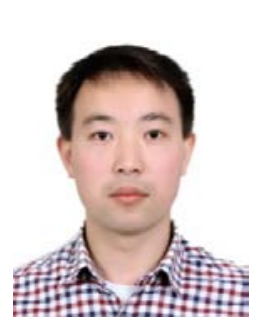

Yihua Hu (M'13) received the B.S. degree in electrical motor drives in 2003, and the Ph.D. degree in power electronics and drives in 2011, both from China University of Mining and Technology, Jiangsu, China. Between 2011 and 2013, he was with the College of Electrical Engineering, Zhejiang University as a Postdoctoral Fellow. Between November 2012 and February 2013, he was an academic Visiting Scholar with the School of Electrical and Electronic Engineering, Newcastle University, Newcastle upon Tyne, UK. He is currently a Research Associate with the Department of Electronic \& Electrical Engineering, University of Strathclyde, Glasgow, UK. He has published more than 20 technical papers in leading journals and conference proceedings. His research interests include PV generation systems, DC-DC/DC-AC converters, and electrical motor drives.

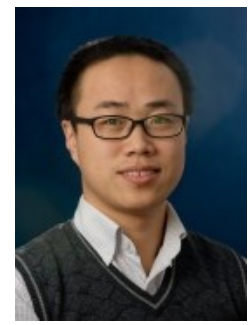

Xueguan Song received the B.S. degree in mechanical engineering from Dalian University of Technology, China, in 2004 and the M.S. and Ph.D. degrees in Mechanical Engineering from Dong-A University, South Korea, in 2007 and 2010, respectively. He is currently an EPSRC Research Associate with the School of Electrical and Electronic Engineering, Newcastle University, Newcastle upon Tyne, U.K. He has published over 30 peer-reviewed papers, 1 book and 1 book chapter on engineering optimization, computational fluid dynamics (CFD) analysis, thermal management of power electronics. He is the recipient of the Best Paper Award at LDIA'13 Conference, Best Poster Awards at CSO'11 and PCO'10 Conferences, and the Honorable Mention Award at ASME-PVP'10 Conference. His research interests include multiphysics design optimization, electronic packaging design, modeling, computational fluid dynamics and thermal management.

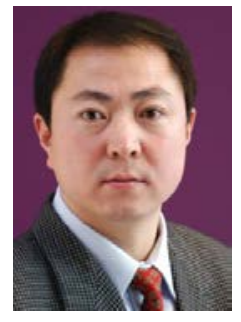

Wenping Cao (M'05-SM'11) (correspondence author) received the B.Eng in electrical engineering from Beijing Jiaotong University, Beijing, China, in 1991; and the Ph.D. degree in electrical machines and drives from the University of Nottingham, Nottingham, U.K., in 2004. He is currently a Senior Lecturer with Queen's University Belfast, Belfast, U.K. He is the recipient of the Best Paper Award at the LDIA'13 Conference. Dr. Cao serves as an Associate Editor for IEEE Transactions on Industry Applications, IEEE Industry Applications Magazine and nine other International Journals. His research interests are in the design and fault analysis of electric machines and drives. $\mathrm{He}$ is also a Member of the Institution of Engineering and Technology (IET) and a Fellow of Higher Education Academy (HEA).

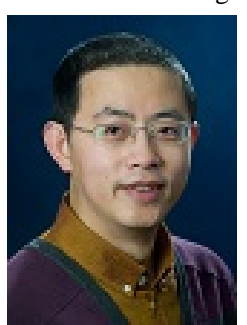

Bing Ji (M'13) received the M.Sc. and Ph.D. degrees in electrical and electronic engineering from Newcastle University, England, in 2007 and 2012, respectively. He was a power electronics engineer with a UK low carbon vehicle company in 2012, working on power drive train and battery management system for hybrid electric vehicles. Since 2013, he has been a Postdoctoral Researcher at Newcastle University, where he is involved in accurate power loss measurement and health management for power electronics. His research interests include reliability study of power semiconductor devices, batteries and power electronics converters, function integration of gate drivers, electro-thermal modelng, thermal management and high power-density converter integration for electric vehicle applications. 